\title{
DECISION MAKING IN THE COASTAL ZONE UNDER AN UNCERTAIN FUTURE
}

\section{KEY MESSAGES}

- Coastal flooding is ranked as the second highest risk of civil emergency in the UK, after pandemic influenza, and poses a hazard to the whole spectrum of society.

- There is a need to increase public and stakeholder trust in flood warning accuracy to build resilience, protect infrastructure, and save lives.

- Better communication of the impacts of coastal hazards associated with predictions of flooding via interdisciplinary methods including citizen science, narratives, storytelling, and audiovisual content is identified as a key tool to improve public awareness and understanding of coastal hazards.

- Uncertainties in flood hazard predictions are inherent and must continue to be identified, but funding and research can do more to minimise them via improved availability of observation data.

- Researchers must continue to be transparent about uncertainties, and work collaboratively with policy makers to better communicate them to end-users and stakeholders by framing risks dependent on their tolerance to uncertainty.

\section{INTRODUCTION}

Coastal flooding is rated as the second highest risk of civil emergency in the UK, after pandemic influenza'. Coastal zones worldwide are subject to short term local variations in sea-level due to astronomical tides, storm surges, wind, waves and rivers ${ }^{2,3}$. These drivers can combine to potentially exceed critical thresholds, such as sea defences, and pose a flooding hazard to coastal communities ${ }^{4}$. Coastal flooding can cause damage to coastal and estuarine infrastructure, communities, ecosystems, and even loss of life ${ }^{5}$. Hydrodynamic, numerical modelling tools are used to identify regions susceptible to coastal flooding under current and future climate conditions. Modelling procedures and data inputs can lead to a range of uncertainties that need to be quantified for the simulations to be meaningful ${ }^{6}$. Reported public scepticism of coastal hazard forecasting and flood warning accuracy may be due in some part to the way that flood dynamics and uncertainties in the computer model simulations of flood hazard are communicated to the end-users ${ }^{7}$. Representing uncertainty is crucial but challenging. Non-specialist audiences can have difficulty in understanding concepts of uncertainty, which can have a detrimental impact on their understanding of key messaging on coastal hazards and risk. The briefing will explore key uncertainties in flooding predictions, and how these can be better communicated to the public and stakeholders. Improved communication can help to increase awareness and encourage behaviour change to build trust in warnings and forecasts. The public need to understand the risk and need to feel in control of decision about how to respond ${ }^{8}$. This in turn helps communities to build resilience to coastal hazards.

\section{Author:}

I Dr Charlotte Lyddon, Coastal Modelling Research Officer, School of Ocean Sciences, Bangor University.

\section{Acknowledgements:}

This briefing draws upon the COP26 Climate Risk Summit panel session 'Communicating the impacts of uncertainty when modelling coastal flooding hazards' on 30th September 2021. The panel included Jennifer Brown, National Oceanography Centre; Sanne Muis, Vrije Universiteit Amsterdam; Ben Gouldby, HR Wallingford and Matthew Palmer, Met Office Hadley Centre. 


\section{WHAT CAUSES COASTAL FLOODING?}

Coastal flooding is caused by extreme sea-levels, which are a made up of a combination of mean sea-level, astronomical tides, storm surges, wind and waves $^{9}$. River discharge is an important component in estuarine environments too ${ }^{10}$. These drivers act of different spatial and temporal scales. For example, mean sea-level is a large scale, global process which can vary from seasonal to centennial timescales. Storm surges, high river discharge, or waves are caused by extreme weather and occur locally from hours to days ${ }^{11}$. In some regions, tropical cyclones cause coastal flooding ${ }^{12}$. In others, it is the magnitude, coincidence, and relative timing of these drivers which elevates water levels above the normal levels and poses a disproportionately large flood hazard $^{13}$. All components of coastal flood hazard will be impacted by future climate change ${ }^{14}$. Sea-level rise will raise the mean and increase the frequency of coastal flooding and may change the tides. Warmer climates will alter wind patterns and storm characteristics, which in turn will impact waves and storm surges. These components all interact and any changes in the mean will alter the frequency and magnitude of flooding events. It is crucial to understand how the drivers of coastal flooding combine under current climate conditions, so that we can assess the impacts of future change.

\section{IMPACTS OF COASTAL FLOODING}

\section{Coastal communities, ports, infrastructure,} ecosystems, and natural resources worldwide are vulnerable to the effects of coastal flooding. Extreme events impact the whole spectrum of society, and cause disruption, damage, and event loss of life. These events can also have far-reaching implications for pollution, water quality, and health. In the United Kingdom, coastal flooding has an annual cost of $\sim £ 2.2$ billion for flood management and emergency response ${ }^{15}$. Several of the world's major cities and industrial centres are located at the coast of steep catchments where there is a risk of flooding from extreme weather events, e.g., Tokyo/Yokohama ${ }^{16}$. Improved estimates of the drivers of flood hazard are essential for flood emergency response, flood risk policymaking, disaster risk reduction, environmental impact assessments and engineering practices.

\section{UNDERSTANDING COASTAL FLOODING HAZARDS}

Numerical modelling tools can be used to simulate the drivers and impacts of coastal flooding hazards. Regional and global scale models, such as NEMO and WAVEWATCH III, are used over timescales of days to decades to simulate large-scale processes such as atmospheric pressure, wind speed, and ocean circulation ${ }^{17,18}$. These processes influence the main drivers of coastal flooding, and outputs can be used to drive smaller local-scale, impact models. Local scale models, such as LISFLOOD-FP and Delft3D, are used at an event timescale (hours to days) to simulate how tides, waves, and rivers combine to increase flood hazard ${ }^{19,20}$. These models are crucial tools for physical scientists to show which areas will flood based on how water moves, height of land, and defences, and can show depth and extent of flooding.

\section{WHAT IS UNCERTAINTY IN COASTAL HAZARD MODELLING?}

Based on an interaction poll, the audience said that 'When scientists report uncertainty in their data they are':

Expressing the degree by which their results $5 \%$ are incorrect

\begin{tabular}{l|l}
\hline Questioning the validity of their results & $5 \%$ \\
\hline Quantifying error and variability & $60 \%$ \\
\hline All the above & $30 \%$
\end{tabular}

$86 \%$ of the audience identified that 'uncertainty in scientific results is inherent in nature.'

Uncertainty is not new phenomenon. Different models, input data, and modelling procedures used to simulate coastal flooding hazards can generate different results or lead to a spread of results ${ }^{6,21}$. This can render their value in flood hazard assessments less useful. Estimates of the magnitude and timing of coastal flooding are uncertain in the sense that there is a lack of certainty that a flood hazard map is without error. Uncertainty in numerical modelling simulations can be a problem for coastal managers and policy makers who rely on accurate and timely predictions for design of coastal defences, early warning systems and evacuation orders ${ }^{22,23}$. There is a need to identify and quantify these uncertainties for coastal flood hazard simulations to be meaningful, and to raise awareness and build preparedness for future hazards in a national context.

\section{WHY IS IT IMPORTANT TO COMMUNICATE UNCERTAINTIES?}

91\% of the audience voted that 'uncertainty in scientific results should be reported even when error is very small.'

Uncertainty is a concept that can be challenging to describe, explain, and understand. Reported public scepticism of coastal hazard forecasting and flood warning accuracy may be due in some part to the way that uncertainties in the computer model simulations of flood hazard are communicated to the end-users. Public scepticism about whether a flood warning or evacuation order is accurate can lead to instances of these directives being ignored. This puts people's lives in danger. 
Uncertainties are often characterised by the centre part of a distribution curve; however rare and extreme events are characterised in the upper tail. These tail risks cannot be robustly quantified with current scientific understanding, which makes it challenging to talk to stakeholders. The best method to quantify and represent or visualise uncertainty, both at the centre and upper tail, remains unclear. This is a challenge related to coastal flood hazard modelling worldwide and must be accounted for in disaster risk reduction (DRR) and adaptation measures ${ }^{24}$.

\section{WHAT ARE THE BIGGEST SOURCES OF UNCERTAINTY IN CURRENT COASTAL HAZARD MODELLING?}

A wordcloud was generated based on audience opinions of what the biggest uncertainties in current coastal hazard modelling are. The key uncertainties identified in the wordcloud and discussion have been split into two groups: data input and model errors. Data input and modelling procedures can lead to a wide range of uncertainties that need to be identified, understood, and quantified for simulations to be meaningful.

\section{Data input}

- Numerical and statistical models can be used to compute the probability of extreme values and events $^{25,26}$. Extremes have always been uncertain; using 30-years of data to estimate very lowprobability events will always introduce uncertainty. Extrapolating extreme values into the future can be a significant source of uncertainty. Understanding how the frequency of a 1 in 100-year storm will change into the future, or when will a 1 in 100-year event occur more regularly is a key challenge.

- Observation data physical phenomenon is a key component of coastal hazard modelling; it can be used to understand controlling processes and changes. This data is used to force models, to validate models which ensures results are representative of real life, or for data assimilation to improve the accuracy of forecasts.

Bathymetry represents the topography of the bottom of the sea and must be representative of the physical environment being modelled to ensure outputs are accurate. LiDAR data is a useful tool, but can be patchy and inaccurate at the coast, leading to researchers having to interpolate or make a best estimate of channel depth at the coast.

- River discharge is an important driver of coastal flood hazard in estuarine environments. At present there is a lack of modelled river data to accurately analyse these drivers in estuaries worldwide and to estimate the impacts of compound flood hazards.
There is a lack of understanding about the processes which control wave overtopping at sea defences and natural coastlines ${ }^{27}$. This is a key process that needs to be resolved to ensure that impacts of waves are accurately captured at engineered and naturally defended coastlines ${ }^{28}$.

social and economic data

validation data cascades

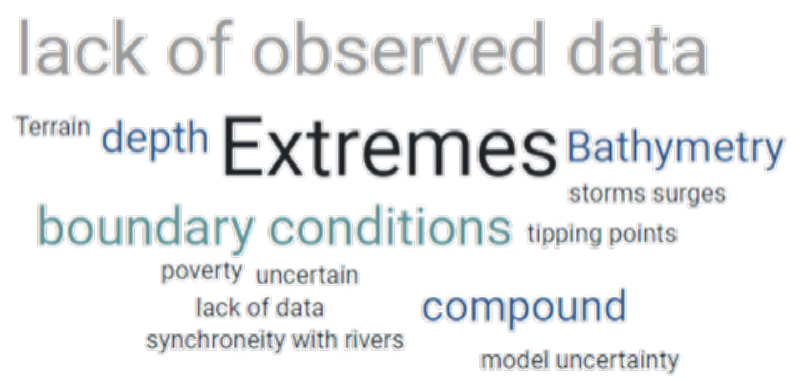

Figure 1: Results from the interactive wordcloud to identify the biggest uncertainties in current coastal flood hazard modelling.

\section{Model errors}

- A lack of appropriate spatial and temporal resolution in models, e.g., representation of complex coastlines and river discharge, can lead to errors in model results.

- A misrepresentation of the physical processes controlling changes at the coast can lead to errors.

\section{WHAT ARE FUTURE UNCERTAINTIES?}

There is also great uncertainty about future drivers and impacts of climate hazards. Sea-level rise will change interactions and drivers of coastal flooding hazard, but the exact impacts will depend on the local context and environmental conditions ${ }^{29}$. It is agreed that sea-level rise is likely to increase the frequency of flooding events ${ }^{30}$ cause significant economic and humanitarian challenges in the coastal $z^{2} e^{20}$. Not every location will experience the same sea-level drivers at the same time. Site specific projections of sea-level rise vary around the UK ${ }^{31}$, and worldwide ${ }^{2}$. Future greenhouse gas emissions, icesheet melt, model uncertainty (due to sea-level processes) and scenario uncertainty (based on certain climate scenarios) contribute to challenges in projecting future changes ${ }^{32}$. Different climate models will produce different results, therefore there is a need to use multiple models and assess where do they agree and disagree? 


\section{WHAT CAN BE DONE TO ADDRESS UNCERTAINTIES?}

Recommendations were made about ways to reduce uncertainty in data used to support decision making. Some uncertainties can be constrained and more can be done to reduce them in model simulation e.g., improved observation data.

There is a strong call for investment in improved observation and monitoring of coastal hazards at higher spatial and temporal resolution. Improved observation data (more observation points, recording at sub-hourly timescales) is key to support modelling work to develop timely and accurate early warning systems and to understand how past events might look under future climate conditions.

- Tide gauge records are still relatively sparse along the UK coastline as much additional observation data as we can get is needed to understand the controlling processes in tide gauge records. Significantly more work is needed to understand site-specific sea-level projections in the context of what the observed processes and those changes we are seeing today.

- Beach levels heavily influence overtopping rates. There are comprehensive archives of beach profiles collected by local authorities, but these are not accurate or up to date. Beach levels are crucial for flood forecasting on sandy coastlines. Citizen science data gathering can provide images of benchmarks of beach levels e.g., CoastSnap ${ }^{33}$, can act as observations on their own. However more work is needed to integrate images of beach levels and feed these into wave overtopping tools for beach management ${ }^{34}$.

- Improved collaboration and commitment are needed worldwide to publish and share monitoring datasets to global data centres. Collaboration can support the use of new methods, including utilising high-performance computing (e.g., machine learning) and next generation of climate models, and design of co-ordinated model experiments to better understand flooding scenarios.

Investment in the development of systematic and comprehensive risk frameworks across all sectors can help to identify the tolerance of infrastructure, communities, and natural environments to risk and uncertainty ${ }^{35,36}$. Risk framing is context and stakeholder specific. Adaptive measures are dependent on stakeholder's tolerance to uncertainty ${ }^{37}$. For example, the nuclear energy industry has a very low risk tolerance and cannot afford to bet against certain levels of sea-level rise. There is a need to be cautious with planning. Other applications and infrastructure can take a more adaptive approach; plans can be implemented to see how they respond to certain environmental conditions, and then the next stage of changes can be planned for.
This adaptive cycle can continue indefinitely but is dependent on the timescale of interest and lifetime of infrastructure. Risk frameworks present as a useful tool to assess appropriate adaptation measures to individual communities and hazards. Consideration must be made for the fact that the British coastline has already been adapted to mitigate damages from extreme events. This makes it more challenging to understand the additional risk of sea-level rise now because there's adaptation trying to mitigate impacts. There is a need to disentangle this. Further to this, the more data and models added into decision making processes, the more uncertain it becomes. For example, converting sea-level to damages can complicate the process and increase uncertainty.

\section{HOW CAN UNCERTAINTIES BE BETTER COMMUNICATED?}

There remains public scepticism about the impacts of climate change, which highlights first need to improve how the basic premise of coastal hazards are communicated.

\section{Communicating coastal hazards:}

Improved communication on the impacts of coastal flooding is needed to build public understanding in the severity of flooding hazards, and trust in early warning systems and forecasts. Research needs to place stronger emphasis on community engagement and personal or community responsibility for flood hazard awareness and resilience planning ${ }^{38,39}$.

The greatest challenge is trying to communicate the impacts of coastal hazards with a range of different audiences. New methods are needed to identify different ways flooding hazard can be communicated to different end-user groups. Expertise from social scientists, humanities, and arts should be utilised and collaboration encouraged ${ }^{40}$. These collaborations can help support the following:

- The use of case studies and personal stories, and art, photography, and audio-visual content can help audiences to see, feel, and hear the impacts of future coastal flooding hazards ${ }^{41,42}$. These methods can remove a reliance on documentation and reports, which can be harder for end-users to navigate. 
- Physically based storylines and narratives can be powerful tools to communicate when and how flooding occurs, and potential impacts ${ }^{8}$. These can illustrate a range of different possibilities about sea-level rise or coastal flooding and do not need to give a quantitative estimate of the likelihood of that outcome ${ }^{43}$. It is compelling to hear someone's personal story, and we will increasingly see communities displaced by coastal flooding, and climate refugees. Narratives will play a key future role in communication and helping people to understand flood dynamics and know what to do during a flood ${ }^{44}$.

What does someone's future look like?

What are the impacts of climate risks on them?

- Reimagining and reframing scientific results can support improved communication of coastal hazards. Recent research has shown how impacts of a historical tropical cyclone event in 2012 may change under different climate conditions i.e., with increase temperature and sea-level rise ${ }^{45}$. The public can remember and relate to the historical event; they know in 2012 they were hit by a tropical cyclone, and their house was flooded or nearly flooded. If this event happened again in 10 years, then sea-level rise would cause the event to be much more extreme. Communicating risk in a different way can be a valuable tool to educate about potential impacts and changes.

\section{Communicating uncertainty:}

There are many gaps and challenges in current methods used to communicate uncertainties to wider audiences. Physical scientists must continue to be clear and communicate about limitations of models and projections. Communication must be transparent about what we cannot know. Audiences are keen to understand uncertainties related to climate risks and it is the job of scientists and policy makers to ensure it is framed in appropriate ways.

Predictions of coastal flood hazards result from a chain of models (Figure 2). These chains of models cause a cascade of uncertainty. Outputs from model are used to force another mode ${ }^{25}$. Uncertainty gets bigger and bigger as the modelling chain keeps moving forward to the coastal flood hazard ${ }^{46}$. This is a problem and a challenge to communicate. There is a need to understand this accretion of uncertainty. Future research would benefit from identifying specific examples of uncertainty in this chain for flooding events. Outputs should communicate that there is some uncertainty in the exact details of how a flooding event might play out, and examples of uncertainty across a distribution can help this.
Based on an interactive poll, the audience said that 'I would rather know about uncertainty related to climate change':

As a range of values (e.g., sea-level may rise $39 \%$ up to $3 \mathrm{~m}$, but could be as low as $50 \mathrm{~cm}$ )

Related to certain impacts (e.g., coastal flooding hazards will vary worldwide due to the nature of SLR)

Probability distribution (e.g., shape of sealevel rise distribution in the tail)

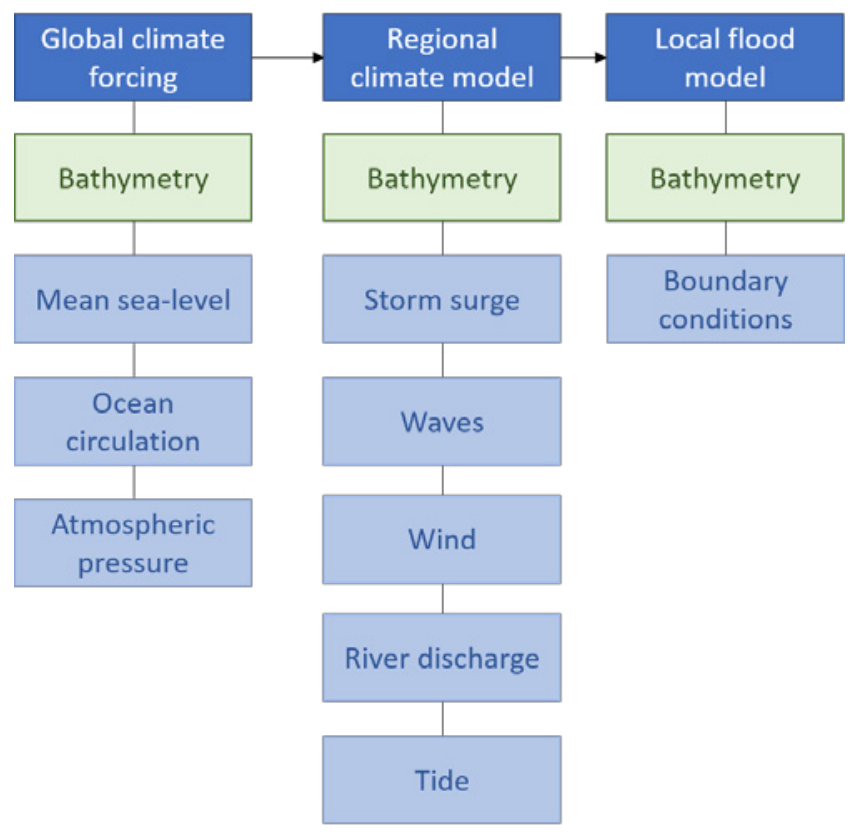

Future climate conditions

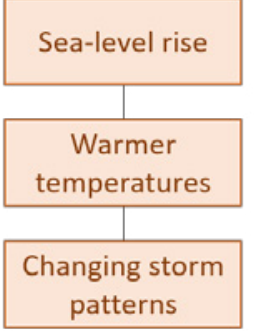

Figure 2: Coastal flood hazard modelling chain; all components have associated uncertainty. 
Physical scientists are used to presenting outputs to experts. There is currently little interaction with wider audiences. There is a wide range of audiences and potential end-users relying on coastal flooding data. These different end-users and stakeholders need to be able to process, assimilate, and use information about uncertainty, or datasets with inherent uncertainty, to support decisions. There is a real need for wider interaction, and this would be welcomed in the physical science disciplines.

Based on an interactive poll, the audience said that 'I find it easiest to uncertainty in future flood hazard zonation when it is:':

Visualised as a series of maps $70 \%$

Expressed as values (e.g., varying depth and 20\% extent) plotted in a graph

Described in a narrative $10 \%$

- Maps are powerful and crucial tools for communicating flooding hazards. It can be easier to process visual aids 47. Little expert knowledge is needed to interpret maps, and they can be designed in ways to appeal to different audiences. However, caution is still needed when using maps.

- Maps which show flood depths associated with an extreme sea-level or wave condition can be misleading. These are termed deterministic maps. They can give an overly precise representation of flood depth, without accounting for sources of uncertainty.

People observe different things when they look at a map, and the spatial scale of a map must be clearly explained. A map representing extreme global sea-level may be true at a larger scale, but may not be true at a smaller, local scale. Maps at different scales are used to answer different questions, and these must be accounted for to ensure key messages are retained.

- Graphs and figures are not as compelling as stories but are still a necessity. Communication specialists can help to identify appropriate terminology to use when working with specific audiences. The terms 'risk' and 'uncertainty' can mean different things to scientists vs. policy makers, or across different policy areas. New collaborations can help with the design of appropriate figures which communicate key messages. Figures should be designed back to front; first identify the key message that should be conveyed, and then design the figure to convey that.

\section{Implications for policy}

There is an absolute necessity for nations worldwide to commit to climate change adaptation. Action must be taken to protect millions of people.

The magnitude and frequency of coastal flooding events will increase, putting the lives of millions at risk.

Coastal managers and local authorities must be provided with the tools to implement risk frameworks at a range of spatial and temporal scales, to support resilience and adaptation strategies.

Future policy to mitigate the impacts of coastal flooding must be based on strong evidence. It is recommended that future funding supports the following.

- Research that will build links between physical scientists, social scientists, arts, and humanities. There is a need to first understand if an interdisciplinary strategy can work at a local scale to educate about flood hazards. Has it worked in the past elsewhere? Workshops which build collaborations and networks between researchers and local arts, photography, or history groups would support this.

- Investment in citizen science initiatives, which engage and empower the public with the reality of coastal hazards in their locality. Funding is needed to support development of methods to integrate data collected from citizen science initiatives into models as boundary conditions and validation data.

- There is great value in modelling studies which aim to understand how past extreme coastal flooding events occurred, and how they might look under future climate change. This research can help to develop local scale understand of the drivers of coastal flooding, to support adaptation and mitigation strategies.

Communicating uncertainty is a two-way conversation. Elected leaders must engage with scientists to transform research outputs into effective policy. It is the responsibility of scientists to ensure policy makers have the information they need to communicate hazards to the public. But it is the equal responsibility of those in positions of power to ensure they have the information they need to use scientific evidence to inform changes. Decisions need to be made for the coming decades, and not just the length of elected terms. 


\section{REFERENCES}

1. UK Gov. National Risk Register. https://assets publishing.service.gov.uk/government/uploads/ system/uploads/attachment_data/file/952959/6.6920_ CO_CCS_S_National_Risk_Register_2020_11-1-21-FINAL. pdf (2021).

2. Oppenheimer, M. et al. Sea Level Rise and Implications for Low Lying Islands, Coasts and Communities. in (2019).

3. Woodworth, P. L. et al. Forcing Factors Affecting Sea Level Changes at the Coast. Surveys in Geophysics 40, 1351-1397 (2019).

4. Lyddon, C. E., Brown, J. M., Leonardi, N. \& Plater, A. J. Sensitivity of Flood Hazard and Damage to Modelling Approaches. Journal of Marine Science and Engineering 8, (2020).

5. Robins, P. E. et al. Compound Flooding: Dependence at Sub-daily Scales Between Extreme Storm Surge and Fluvial Flow. Frontiers in Built Environment 7, 116 (2021).

6. Lewis, M., Horsburgh, K. \& Bates, P. Quantifying the Uncertainty in Future Coastal Flood Risk Estimates for the UK. Journal of Coastal Research 276, (2011).

7. Atkinson, P. et al. State-of-the-art in Risk Mapping. in (2012).

8. Rollason, E., Bracken, L. J., Hardy, R. J. \& Large, A. R. G. Rethinking flood risk communication. Natural Hazards 92, 1665-1686 (2018).

9. Pugh, D. T. Tides, Surges and Mean Sea Level. (Wiley, 1987).

10. Ward, P. J. et al. Dependence between high sea-level and high river discharge increases flood hazard in global deltas and estuaries. Environmental Research Letters 13, 084012 (2018).

11. Haigh, I. D. et al. Spatial and temporal analysis of extreme sea level and storm surge events around the coastline of the UK. Scientific Data 3, 160107 (2016).

12. Paerl, H. W. et al. Recent increases of rainfall and flooding from tropical cyclones (TCs) in North Carolina (USA): implications for organic matter and nutrient cycling in coastal watersheds. Biogeochemistry 150, 197-216 (2020).

13. Bevacqua, E. et al. Higher probability of compound flooding from precipitation and storm surge in Europe under anthropogenic climate change. Science Advances 5, eaaw5531 (2021).

14. Kirezci, E. et al. Projections of global-scale extreme sea levels and resulting episodic coastal flooding over the 21st Century. Scientific Reports 10, 11629 (2020).

15. Penning-Rowsell, E. C. A realistic assessment of fluvial and coastal flood risk in England and Wales. Transactions of the Institute of British Geographers 40, 44-61 (2015).

16. Koyama, N.\& Yamada, T. A Proposed Simultaneous Calculation Method for Flood by River Water, Inland Flood, and Storm Surge at Tidal Rivers of Metropolitan Cities: A Case Study of Katabira River in Japan. Water 12, 1769 (2020).

17. Graham, J. A. et al. AMM15: a new high-resolution NEMO configuration for operational simulation of the European north-west shelf. Geosci. Model Dev. 11, 681-696 (2018).
18. Saulter, A. N., Bunney, C., King, R. R. \& Waters, J. An Application of NEMOVAR for Regional Wave Model Data Assimilation. Frontiers in Marine Science 7, 897 (2020).

19. Lyddon, C., Brown, J. M., Leonardi, N. \& Plater, A. J. Flood Hazard Assessment for a Hyper-Tidal Estuary as a Function of Tide-Surge-Morphology Interaction. Estuaries and Coasts 41, (2018).

20. Barnard, P. L. et al. Dynamic flood modeling essential to assess the coastal impacts of climate change. Scientific Reports 9, 4309 (2019).

21. Cowell, P. J. \& Zeng, T. Q. Integrating Uncertainty Theories with GIS for Modeling Coastal Hazards of Climate Change. Marine Geodesy 26, 5-18 (2003).

22. Apel, H., Thieken, A. H., Merz, B. \& Blöschl, G. Flood risk assessment and associated uncertainty. Natural Hazards and Earth System Sciences 4, 295-308 (2004).

23. Lyddon, C., Brown, J. M., Leonardi, N. \& Plater, A. J. Uncertainty in estuarine extreme water level predictions due to surge-tide interaction. PloS one 13, e0206200e0206200 (2018).

24. Parodi, M. U. et al. Uncertainties in coastal flood risk assessments in small island developing states. Nat. Hazards Earth Syst. Sci. 20, 2397-2414 (2020).

25. Gouldby, B. P., Liu, Y., Forster, A., Hornsby, J. \& Mitchell, C. Uncertainty and sensitivity analysis of a coastal flood risk modelling chain. in EVAN17-19 (2019).

26. Muis, S. et al. A High-Resolution Global Dataset of Extreme Sea Levels, Tides, and Storm Surges, Including Future Projections. Frontiers in Marine Science 7, 263 (2020).

27. Pullen, T. et al. A generic and practical wave overtopping model that includes uncertainty. Proceedings of the Institution of Civil EngineersMaritime Engineering 171, 109-120 (2018).

28. Stokes, K. et al. Forecasting coastal overtopping at engineered and naturally defended coastlines. Coastal Engineering 164, 103827 (2021).

29. Wahl, T., Jain, S., Bender, J., Meyers, S. D. \& Luther, M. E. Increasing risk of compound flooding from storm surge and rainfall for major US cities. Nature Climate Change 5, 1093-1097 (2015).

30. Vitousek, S. et al. Doubling of coastal flooding frequency within decades due to sea-level rise. Scientific Reports 7, 1399 (2017).

31. Lowe, J. et al. UKCP18 Overview report. (2018).

32. Taherkhani, M. et al. Sea-level rise exponentially increases coastal flood frequency. Scientific Reports 10, 6466 (2020)

33. Hart, J. \& Blenkinsopp, C. Using Citizen Science to Collect Coastal Monitoring Data. Journal of Coastal Research 95, 824-828 (2020).

34. Brown, J. M. et al. Novel use of social media to assess and improve coastal flood forecasts and hazard alerts. Scientific Reports 11, 13727 (2021).

35. Seneviratne, S. et al. Changes in climate extremes and their impacts on the natural physical environment. in (2012).

36. Najafi, M. R., Zhang, Y. \& Martyn, N. A flood risk assessment framework for interdependent infrastructure systems in coastal environments. Sustainable Cities and Society 64, 102516 (2021). 
37. Hall, J. \& Solomatine, D. A framework for uncertainty analysis in flood risk management decisions. International Journal of River Basin Management 6, 85-98 (2008).

38. Eden, S. E. Individual Environmental Responsibility and its Role in Public Environmentalism. Environment and Planning A: Economy and Space 25, 1743-1758 (1993).

39. Nye, M., Tapsell, S. \& Twigger-Ross, C. New social directions in UK flood risk management: moving towards flood risk citizenship? Journal of Flood Risk Management 4, 288-297 (2011).

40. Brown, J. D. \& Damery, S. L. Managing Flood Risk in the UK: Towards an Integration of Social and Technical Perspectives. Transactions of the Institute of British Geographers 27, 412-426 (2002).

41. Kuser Olsen, V. B. et al. An approach for improving flood risk communication using realistic interactive visualisation. Journal of Flood Risk Management 11, S783-S793 (2018).

42. Wicks, D. New Jersey: Using the Arts to Communicate about Coastal Flooding. https://nasaa-arts.org/ newsletter/2020-nasaa-notes-issues/december2020-nasaa-notes/new-jersey-using-the-arts-tocommunicate-about-coastal-flooding / (2020).
43. Wadey, M. P. et al. Coastal flood analysis and visualisation for a small town. Ocean \& Coastal Management 116, 237-247 (2015).

44. Becu, N. et al. Participatory simulation to foster social learning on coastal flooding prevention. Environmental Modelling \& Software 98, 1-11 (2017).

45. Muis, S., Verlaan, M., Winsemius, H. C., Aerts, J. C. J. H. \& Ward, P. J. A global reanalysis of storm surges and extreme sea levels. Nature Communications 7, 11969 (2016).

46. Vousdoukas, M. I. et al. Understanding epistemic uncertainty in large-scale coastal flood risk assessment for present and future climates. Natural Hazards and Earth System Sciences 18, 2127-2142 (2018).

47. de Moel, H., van Alphen, J. \& Aerts, J. C. J. H. Flood maps in Europe \&ndash; methods, availability and use. Natural Hazards and Earth System Sciences 9, 289-301 (2009).

\section{THE COP26 UNIVERSITIES NETWORK}

This briefing is produced in association with the COP26 Universities Network, a growing group of more than 80 UK-based universities and research centres working together to help deliver an ambitious outcome at the UN Climate Summit in Glasgow and beyond.

The Climate Risk Notes series is an outcome of the Climate Risk Summit. The Summit aimed to bring key information on the risks of climate change, and their communication to decision-makers, to the attention of a wider audience ahead of COP26. The Climate Risk Notes crystallise and expand on the learnings from the Summit.

The briefing represents the views of its authors (listed on page one) and not necessarily that of every University or institution participating in the network. For more information about the COP26 Universities Network, please contact cop26universities@imperial.ac.uk

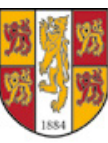

P R I F Y S G O L

\section{B A N G O R}

UNIVERSITY

\section{HOW TO CITE THIS PAPER}

Lyddon, C. (2021). Decision making in the coastal zone under an uncertain future. COP26 Universities Network Climate Risk Note. 